\title{
Vida e trabalho na indústria de petróleo em al to mar na Bacia de Campos
}

\author{
Life and work at the petroleum industry in Campos Basin
}

Rose M ery dos Santos Costa Leite ${ }^{1}$

\footnotetext{
${ }^{1}$ Petróleo Brasileiro S.A Petrobras. Av. Almirante Barroso 81/170 andar, Centro. 20031-004 Rio de Janeiro RJ.

rose.milk@yahoo.com.br
}

Abstract In this paper we detach the subject of confinement as a central axle in the activity at maritimeoil platforms of Campos Basin, in north region of the Rio de Janei ro state. This work reality that determines for offshore workers, as they are known, a rupture between two different moments in there lives: the period of fourteen days in the sea and thelifein land per twenty one days. Weadopt as material empiricist, the research carried out on this universe, detaching here the way as these professionals understand the conditions of confined work in which they are submitted. Key words Confinement, Offshore oil industry, Work organization
Resumo N esteartigo, destacamos a temática do confinamento como um eixo central na atividade realizada nas plataformas marítimas de petróleo da Bacia deCampos, na região norte do Estado do Rio de Janeiro. Essa é uma realidade de trabalho que determina para os trabalhadores offshore, como estes são conhecidos, uma ruptura entre dois momentos distintos em suas vidas: o período de catorze dias de trabalho no mar ea vida em terra por 21 dias. Adotamos como material empírico a investi gação que conduzi mos sobre este universo, destacando aqui o modo como estes trabal hadores interpretam as condições do trabalho confinado aos quais estão submetidos.

Palavras-chave Confinamento, Indústria petrolífera offshore, Organização do trabalho 
Introdução

Este texto aborda parte de uma pesquisa ${ }^{1}$ sobre a realidade dos trabalhadores das plataformas marítimas de petróleo, próprios da Petrobras, na Bacia de Campos, região do nortefluminense do Estado do Rio de Janeiro, conhecidos como trabalhadores offshore.

Inicialmente, tínhamos o objetivo de realizar a pesquisa empírica a bordo. No entanto, a justificativa apresentada na época pela Petrobras de que as plataformas estavam com superlotação inviabilizou tal iniciativa. Assim, buscamos um caminho mais factível que não comprometesse a qualidade do trabalho e não fosse impeditivo para seu desenvolvimento, uma vez quejá tínhamos tido várias oportunidades, em outros momentos, de vivenciar a vida offshore.

Dessa forma, a realização das entrevistas com os trabalhadores durante o seu período de folgas, em terra, mesmo que pudesse trazer algumas dificuldades iniciais de contato, interesse e disponibilidade, era a alternativa mais viável, que foi posteriormente confirmada, para realização da pesquisa empírica.

O btivemos autorização da Petrobras para darmos início ao desenvolvimento do trabalho, sem nenhum tipo de interferência e intermediação da empresa, resguardando totalmente a identidade dos trabal hadores entrevistados.

\section{A indústria petrolífera offshore- querealidadeéessa?}

Toda trajetória de exploração e produção de petróleo em alto mar, nessa região, teve início na década de setenta. Ao longo desses anos, a Petrobras foi se configurando como setor de ponta no cenário offshore.

A escalada progressiva da Bacia de Campos, de conquista do fundo do mar, transformou essa região numa gigantesca e poderosa área industrial, onde são utilizadas as mais novas tecnologias em produção de petróleo em águas ultraprofundas, que servem de referencial para a indústria petrolífera mundial.

Todo esse pioneirismo posiciona a Petrobras como líder em tecnologia de extração de petróleo no mar, no setor petrolífero brasileiro e, atualmente, a coloca em quarto lugar no ranking das maiores petrolíferas de capital aberto do mundo, como a terceira maior empresa do continente americano em valor de mercado e ocupa o sexto lugar entre as maiores empresas do mundo.
A área de petróleo offshore, assim como outras indústrias de processo contínuo, são caracterizadas pela não interrupção de seus processos eoperações duranteos 365 dias do ano, exigindo apenas substituições nas equipes detrabal ho, que se revezam de forma ininterrupta. Essas condições de trabal ho assumem complexidades consideráveis no universo offshore, uma vez que em todas as atividades e etapas produtivas existem "riscos intrínsecos e variados", provenientes dos numerosos processos físicos e químicos que compõem a lógica industrial.

Ao pesquisar sobre a indústria petrolífera, Sevá Filho² define o risco nessa área como sendo "técnico, coletivo e ambiental". Considera que riscos técnicos são aqueles que tenham origem em eventos tecnológicos e em condições organizacionais ou que tenham origens naturais agravadas pela tecnologia e pela organização; que vitimaram e podem vitimar indi víduos e coletividades humanas dentro e fora dos locais de produção; e que já resultaram e resultarão em alterações ambientais significativas, sejam eventos agudos, destrutivos, sejam processos latentes, combinaçõesinéditas, efeitos cumulativos em parte desconhecidos ${ }^{3}$.

Assim, o espaço offshoreestá configurado por processos eatividades complexas, perigosas, contínuas e col etivas e que envolvem os mais diversos riscos. Acrescenta-se a essa complexidade a permanência durante catorze dias em confinamento em al to mar, o que eleva substancialmente as proporções do resultado dessa equação para os trabalhadores.

Cabe destacar que a Constituição Brasileira de 1988, em seu artigo 7 inciso XIV, previu alteração na jornada de seis horas para o trabalho realizado em turnos ininterruptos de revezamento (TIR), "salvo negociação coletiva" ${ }^{4}$. Sendo assim, a partir do acordo coletivo de trabalho de 1989, assinado entre a Petrobras e os sindicatos dos petroleiros, o regime offshore foi alterado para jornadas de doze horas durante catorze dias, de sembarque no décimo quinto dia e vinte dias de folgas, o conhecido regime de trabalho 14 por 21. Essa mudança não atingiu os trabalhadores terceirizados que ainda permanecem, até os dias de hoje, com a mesma relação trabalho/folga adotada pela Petrobras antes da mudança constitucional, ou seja, 14 por 14.

Diante de toda complexidade existente nesse universo singular, nos deteremos aqui a discutir somente sobrea questão do confinamento offshore, ao qual estão submetidos durantecatorzedias esses trabalhadores. 


\section{Como chegar à plataforma}

Ostrabalhadores offshorepodem residir em qualquer lugar do Brasil ou do exterior, a ponto de alguns levarem de dois a três dias de viagem no trajeto entre a sua residência e as plataformas. Portanto, juntam-se homens oriundos de locais eculturas diferentes, expectativas diversas, trajetórias e histórias singulares, em um mesmo espaço físico por catorze dias, tendo como meta de trabalho e de vida realizar tarefas que levem à produção de óleo e gás em águas profundas ou ultra-profundas, bem como suplantar os próprios recordes já alcançados.

0 deslocamento entre 0 aeroporto, situado na cidade de M acaé ou de Campos dos Goycatazes, no Estado do Rio de Janeiro, e a plataforma se dá em vôos de helicóptero, com duração entre quarenta e noventa minutos. Quando se chega ao aeroporto, já existe toda uma padronização de procedimentos a serem seguidos. 0 trabalhador localiza num quadro de avisos o seu vôo e dirige-se ao local de pesagem dos passageiros e das bagagens. A bagagem está limitada a quinze quilos, é pesada e vistoriada, uma vez que é, terminantemente, proibido o transporte, por exemplo, de armas, bebidas e drogas.

Posteriormente, após a chamada de seu vôo, o trabalhador encaminha-se para a área interna de espera, onde é submetido à revista por um segurança. Algum tempo depois, já na aeronave, recebe o colete inflável, a ser colocado imediatamente, e assiste a uma pequena palestra de segurança, conhecida como briefing, ministrada pelo co-piloto, com informações sobreos procedimentos e os comportamentos a serem adotados desde a entrada na aeronave, durante o período de viagem eao descer do helicóptero na plataforma.

Quando o helicóptero pousa no heliporto da plataforma de destino, será encaminhado a um local, no casario da Unidade, onde é feita a identificação e posteriormente assiste a um segundo briefing de segurança obrigatório, realizado pelo técnico de segurança, queorienta sobreos procedimentos a serem seguidos em caso de alarme.

Em seguida, o trabalhador precisa se dirigir a um local denominado ponto de reunião para colocar um cartão que recebeu na chegada à plataforma. 0 ponto de reunião é lugar de referência para o qual o trabalhador tem que se conduzir em caso de evacuação da plataforma em situações deemergência.
O confinamento - vida etrabalho

Independentemente de se chamar Antônio, Manoel ou Francisco, a partir do momento que cada um descer do helicóptero e pisar no heliporto da plataforma, será por catorze dias somente um trabalhador offshore: trabalhadores submetidos à mesma condição de confinamento. Durante esse período, permanecerão sem contatos pessoais com os amigos de terra, familiares, etc., sem ingerirem nenhuma bebida alcoólica, folgarem os finais de semana e feriados, comemorarem datas importantes, assistirem de perto os seus times jogarem emuito menos faltarem ao trabaIho, pois estarão isolados, envoltos pelo metal, pelo azul do céu e o azul-marinho do mar.

A temática do confinamento se articula à localização geográfica das plataformas e ao regime de trabalho, 14 por 21. Esse regime, ao mesmo tempo em que determina uma dissociação radical entre a vida pública, representada pelo embarque, ea vida privada, pelo desembarque, cria também para o trabalhador, no período de catorze dias de embarque, uma fusão desses dois espaços e tempos vividos: o público e o privado. $\mathrm{N}$ a plataforma, a vida é compartilhada vinte e quatro horas por dia durante os catorze dias, 0 que faz com que não se tenha, em nenhum momento, a percepção de privacidade. D emarcações meramente formais entre público (trabalho) e privado (descanso) são representadas por vestuário mais leve e descontraído após a jornada, em substituição ao uniforme laranja, conversa informal, jogos, TV, leitura de jornais, etc. ou mesmo o sono. Entretanto, todos mostram em verdade pouca efetividade, pois se parte dos trabalhadores descansam, os demais continuam trabalhando e mantendo contato com os que estão de folga, além de todas as condições do trabalho confinado aos quais todos estão submetidos.

Essa convivência, no ambiente offshore, sob o ponto de vista da espacialidade e da temporalidade, remete ao conceito de instituição total adotado por Goffman 5 : U ma instituição total pode ser definida como um local de residência e trabaIho onde um grande número de indivíduos com situação semel hante, separados da sociedade mais ampla por considerável período de tempo, levam uma vida fechada eformalmenteadministrada. [ ...] Seu fechamento ou seu caráter total é simbolizado pela barreira à relação social com o mundo externo e por proibiç̧ões à saída que muitas vezes estão incluídas no esquema físico - por exemplo, portas fechadas, paredesaltas, aramefarpado, fossos, água, florestas ou pântanos ${ }^{5}$. 
Estas instituições são relacionadas por Goffman ${ }^{5}$ em cinco grupos, quais sejam: um primeiro que agrupa instituições que cuidam de pessoas incapazes e inofensivas, como as casas para cegos, velhos, órfãos e indigentes; um segundo responsável por pessoas consideradas incapazes, não de forma intencional, de cuidarem desi mesmas, como sanatórios para tuberculosos, hospitais para doentes mentais e leprosários; um tercei ro que objetiva resguardar a comunidadecontra os perigos intencionais, como cadeias, penitenciárias, campos de prisioneiros de guerra e campos de concentração; um quarto que reúne pessoas com a intenção de realizarem alguma tarefa de trabalho, tais como quartéis, navios, escolas internas, campos de trabalho, colônias e grandes mansões e, por último, as instituições que se destinam a servir de refúgio do mundo e que servem também como locais de formação para religiosos, como abadias, mosteiros e conventos. A partir dessa caracterização, observa-se que o trabalho offshore se insere na descrição do quarto grupo.

Ao se estabelecer uma anal ogia entre as instituições totais e as plataformas, observa-se que independentemente da finalidade de cada uma, 0 confinamento é uma característica comum entre elas. Essesistema fechado, fortementeinstituído e que isola, detém o controle total da vida de seus membros, durante o período de permanência no mesmo.

Uma característica central das instituições totais se refere à ruptura que se dá entre as barreiras que separam as três esferas da vida - dormir, brincar e trabal har. Nesses ambientes, todos os aspectos da vida são desenvolvidos em um mesmo local e submetidos a uma mesma autoridade. Cada etapa da vida diária é realizada na companhia de um grupo relativamente grande de pessoas, que são obrigadas a fazer as mesmas coisas em conjunto, e todas as atividades cotidianas obedecem a horários predeterminados e a um sistema de regras. Assim, estas são planejadas de forma a atender conjuntamente aos obje tivos institucionais, ou seja, cabe a instituição o gerenciamento total da vida de seus membros ${ }^{5}$.

Losicer e Siqueira ${ }^{6}$ concluem que, concomitantementeà existência de convergências entreas instituições totais e as gigantescas máquinas marítimas, também há distinções importantes entre elas, tais como o confinamento contínuo e prolongado das instituições totais e o relativamente curto e intermitente das plataformas; entre um local que produz petróleo, ou seja, uma mercadoria, e um outro de reclusos que só pro- duz técnicas de controle; eas relações detrabal ho entre os embarcados e 0 inexistente entre os internados. Cabe, portanto, enfatizar que não é nosso objetivo afirmar que as plataformas se constituem em instituições totais a partir da conceituação clássica dada por Goffman. Porém, a questão do confinamento é um traço que demarca um elo deidentificação entreestes espaços institucionais, o quevai gerar o denominado "efeito totalizante", identificado por Losicer e Siqueira em seus estudos com a população embarcada. 0 relato que se segue mostra o impacto, nos trabalhadores offshore, desse efeito que os totaliza. A primei ra coisa que você faz quando você embarca é pegar uma fol hinha daquela ali e contando os dias, o tempo passa mais rápido possível. Por queo mais importanteé você desembarcar. Você fica torcendo pra passar logo o dia. Ele quer acelerar o tempo, pra chegar o dia dele ir embora (Trabalhador entrevistado).

Os diferentes espaços da vida estão integrados num mesmo lugar, os participantes com os quais se convive são os mesmos, a autoridade está centrada em uma única pessoa e uns poucos recebem delegação para o representarem e ao mesmo tempo há um planejamento conjunto desses espaços de modo que todos possam usufruí-lo sem interrupção do processo contínuo de produção.

Por se tratar de uma organização produtiva, a lógica instituída que totaliza é demarcada por uma concepção de padronização inerente à natureza dos processos de trabalho, dos procedimentos operacionais e de segurança, mas que também invade a dinâmica das relações entre as pessoas, exigindo que sua população esteja permanentemente no limite de suas capacidades físicas epsíquicas. Agora, são ambientes que padronizam o comportamento, trabalhando no mar, como dentro de uma câmara de mergulho, o que existe em comum é que nossos comportamentos passam a ser padronizados (Trabalhador entrevistado).

Estar submetido a essa ordem produtiva que engloba trabalho e descanso pode ser utilizado como um mecanismo de controle pela equipe dirigente. A conduta adotada pel os seus habitantes em uma determinada esfera da vida interna pode ser usada pelas chefias, a favor ou contra os interesses e necessidades da população interna. Assim, efetivamentenão existeuma delimitação das esferas da vida (descanso e trabalho), pois um comportamento adotado em um determinado âmbito pode favorecer ou prejudicar o trabalhador em outros contextos internos. Se, nas plata- 
formas, não existe dicotomia entre público e privado, o trabalhador durante o seu período de permanência a bordo estará submetido a uma mesma figura de autoridade. Os comportamentos adotados pelo trabal hador, quando se encontra no efetivo exercício de suas atividades profissionais no processo produtivo, pode interferir de forma intrínseca e contraditória nos demais momentos da vida de embarcado, assim como também pode ocorrer o movimento oposto. Essa não dissociação cria, de fato, um estado de vigilância constante que 0 submete psiquicamente a relações controvertidas de exploração e alienação.

A tendência totalizantedehomogeneização de todo espaço offshore invade até a realização de tarefas consideradas simples e comuns, uma vez que a atenção e os cuidados com a complexidade de riscos aos quais os trabalhadores estão expostos favorecem a adoção de uma conduta mais enrijecida.

O obstáculo que as instituições totais colocam entre os homens que habitam os seus espaçoseo mundo externo assinala um primeiro corte que diferencia esse espaço institucional dos demais. $\mathrm{Na}$ vida civil em geral, tanto as rotinas diárias quanto os ciclos de vida não se tornam impeditivos para que um papel que o trabalhador desempenhe não obstrua sua efetividade e suas ligações em outro. No entanto, nas instituições totais, a separação entre os dois mundos perturba a sequência de papéis, pois essa situação pode perdurar por muitos anos. M esmo quando retorna ao mundo civil e restabeleça alguns destes papéis, muitas dessas perdas, por vezes, são irrecuperáveis. Goffman considera que essas perdas apresentam aspectos relativos ao conceito demortecivil eexemplifica esseconceito afirmando que "os presos podem enfrentar, não apenas uma perda temporária dos direitos de dispor do dinheiro e assinar cheques, opor-se a processos de divórcio ou adoção e votar" ${ }^{\prime \prime}$. Nas plataformas, os trabalhadores offshore, em muitas ocasiões quando estão embarcados, são impedidos de exercer um dos direitos fundamentais do cidadão, ou seja, o de ter a oportunidade de exercitar o seu livre-arbítrio ao escolher os seus governantes, por meio do voto ${ }^{7}$.

Pesquisas realizadas com trabalhadores offshore no $\mathrm{M}$ ar do Norte e com os embarcados da Bacia de Campos $^{6}$ sinalizam que o espaço de confinamento pode gerar graves efeitos de despersonalização, uma vez que se caracterizam por "proporcionar aos seus membros um mundo próprio e apresentar uma tendência absorvente ou totalizadora (absorve parte do tempo e do interesse dos seus membros)".

Para o internado, o sentido completo de estar 'dentro' não existe independentemente do sentido específico que para ele tem 'sair' ou ir para fora'. [...] as instituições totais [...] criam e mantêm um tipo espeć́fico de tensão entre o mundo doméstico e o mundo institucional, eusam essa tensão persistente como uma força estratégica no controle dos homens $5^{5}$.

Essa tendência totalizadoraésimbolizada pelo exercício do trabalho na condição de confinamento, relacionado a uma reclusão forçada que, apesar de afastar o trabalhador do convívio sociofamiliar, não édeterminante para impedir ingressos e regressos.

Para Goffman", a instituição total "é híbrido social, parcialmentecomunidaderesidencial, parcialmente formal". Destaca que, em algumas instituições totais, existe uma "espécie de escravidão", pois o tempo integral das pessoas que lá convivem é colocado à disposição da equipedirigente. Sendo assim, o sentido de eu e de posse dessas pessoas podem torná-las al ienadas em sua capacidade de trabalho.

$\mathrm{N}$ as instituições fechadas, as relações verticalizadas e hierarquizadas, na linha de comando, é um outro aspecto relativo ao efeito de despersonalização. Esse comando écentrado numa única figura de autoridade que transmite 0 seu poder por uma cadei a de comando vertical erígida. $\mathrm{Na}$ plataforma, durante o período de confinamento, a gestão total da vida de seus habitantes, mesmo por um período relativamente curto, cabe, exclusivamente, à empresa, tendo como seu representante 0 gerente de plataforma (Geplat). Siqueira Silva ${ }^{9}$ considera que, no caso dos embarcados, a relação com a chefia se torna um dos pontos mais sensíveis para o equilíbrio emocional dos trabal hadores. Corroboramos essa conclusão, uma vez que os trabalhadores consideram que, além das funções gerenciais técnicas, 0 gerente da plataforma (Geplat) também deve exercer um papel de aglutinador das diferenças, para que o trabalhador realizasse suas atividadescom satisfação, o que consequentementeacarreta o aumento em sua produtividade. Acrescentam, ainda, que o espaço offshore não pode ser considerado, exclusivamente, como um local de trabalho, mas de vida por catorze dias.

Registram de forma contundente que a maioria dos gerentes de plataformas "estão muito atrasados no tempo", pois relegam a um segundo plano o lado humano necessário para se con- 
viver e trabalhar em um regime de confinamento. N essa direção, constatam que, muitas vezes, os gerentes partem da premissa que, no trabal ho offshore, só existem equipamentos e procedimentos operacionais e esquecem que precisam dos trabalhadores. Estes, por sua vez, assumindo um papel de sujeito do seu processo histórico, afirmam: "sem a gente lá nada funciona". Assim, ao mesmo tempo em quea palavra éa "revelação de um espaço no qual os valores fundamentais de uma dada sociedade se explicitam e se confrontam", mostram o quanto é particularmente ambígua e contraditória essa realidade de trabal ho.

A partir da correlação de forças entre capital e trabalho, o gerente ou supervisor ocupa essa posição para mediar esses interesses que são intrinsecamente contraditórios. Assim, premissas, diretrizes e metas de produção são definidas e ele, como representante do capital, tem de colocá-las em prática, atendendo aos trabalhadores, de modo que estes aumentem o investimento no trabalho, de forma alienada, ou seja, aumentem a produção. Esses condicionantes Ihes impõem pressões e tensões a serem vivenciadas no dia a dia do trabalho offshore. 0 gerente de terra é um cara mais aberto, aceita sugestões, mas o cara que ta lá, não sei seé porqueégerente, fica maisisolado (Trabalhador entrevistado).

Considerando que todas as frases que dize mos na vida real possuem algum tipo de pensamento oculto por detrás delas ${ }^{10}$, significa também afirmar que a linguagem que se estabelece nas relações entre gerentes e trabal hadores e/ou equipes é perpassada por um processo unilateral eunidirecional, decima para baixo. A linguagem não se constitui exclusivamente da informação, mas do estabelecimento de um processo dialógico nos quais ressaltam "as expressões faciais, os gestos, o tom das vozes e um conhecimento mútuo do tema $[. . .]^{\prime 10}$. Em uma realidade ambígua como é 0 trabalho offshore, a linguagem assume uma importância sem precedentes, pela não dissociação do espaço público e privado.

0 efeito da despersonalização, além de invadir o período de embarque, é também determinantena imposição deinterferências queassolam o período de folgas, conforme depoimento a seguir: Era sempre o outro que tava decidindo a minha vida. Então, há uma despersonalização, igual a prisão, você está sob o controle do outro. Então, éo outro éque decidequando vocêta embarcado, quando você vai desembarcar, vai trocar. Então, você vira um joguete, uma coisa na mão dequem decide, tão mandando você... não há um respeito a pessoa, as convicções dela, os valores dela, isso me marcou profundamente, essa despersonalização, essa coisa de, como se eu fosse mais uma máquina ali, que pode ser trocada (Trabalhador entrevistado).

O sentido de máquina que invade a autoidentificação do trabalhador offshore, além de colocá-lo não como sujeito de sua história, exprime a percepção generalizada de não reconhecimento pelo trabal ho que realizam e descrédito em relação ao quepensam eao quedizem. Athay$\mathrm{de}^{11}$ afirma que "no campo social, o reconhecimento do ser é reconduzido permanentemente pelo reconhecimento do fazer"; na ausên cia deste processo, há uma desestabilização e o sofrimento patógeno surge no lugar do prazer. Corroboramos também com a conclusão de Losicer e Siqueira ${ }^{6}$ de que a"interdição da palavra" éo efeito demaior impacto subjetivo na formação da identidade offshore. Os depoimentos dos trabalhadores entrevistados a seguir ilustram a expectativa dos mesmos de serem valorizados e reconhecidos pelo investimento que fazem no trabal ho.

Ela [empresa] funciona, graças a Deus, pelo coração, pelos braços e pelas pernas, que ela tem que são seus funcionários. Se a empresa não valorizar isso que ela tem, ela não tem nada.

As pessoas se dedicam muito no trabalho, pra produzir óleo e tem pouco retorno, não são reconhecidas, nem valorizadas e nem el ogiadas.

Assim, nas plataformas, existe o sentimento dequeo período de permanência no local detrabalho é tão penoso que não existem saídas e soluções, restam apenas o desejo e a expectativa de que o tempo possa ser acelerado. Dessa forma, os catorze dias passariam a ser um "tempo morto", ou seja, um período de vida inexistente.

A situação de intermitência embarque/desembarque gera a percepção de uma vida sem valor e sem significado, pois al guns papéis desempenhados cotidianamente não podem ser exercidos de forma concomitante com outros; vive-se assim uma "vida não completa". Em algumas instituições totais, como nas prisões enos hospitais para doentes mentais, existe 0 sentimento de que 0 tempo passado na entidade é um tempo perdido, destruído ou tirado da vida da pessoa. "É tempo que precisa ser apagado; éal go que precisa ser cumprido, preenchido ou arrastado de alguma forma" 5 .

Quer queira, quer não, catorze lá dentro equivale a trinta dias porque você fica vinte e quatro horas lá. Você não sai de lá do trabalho e vai pra casa, evai prum hotel flutuante se desligar detodo problema. N ão, você fica lá. A gora, os catorze dias lá realmente são os catorze dias, literalmente, minuto a minuto, segundo a segundo (Trabalhador 
entrevistado).

Esse sentimento se refere não exclusivamente às questões que envolvem as condições de trabaIho, mas principalmente às perdas de contatos sociais. $\mathrm{Na}$ vida social cotidiana, os homens circulam e desempenham vários papéis ao mesmo tempo, o que écompletamente cerceado no regime offshore, dando a percepção de viver, apenas, um pedaço de sua vida. Goffman ${ }^{5}$ considera que as chamadas atividades de distração poderiam minimizar, mesmo que momentaneamente, a situação real desuas vidas e essa percepção detempo "morto".

Normalmente, os homens vivenciam o tempo a partir de situações que demarcam cotidianamente suas vidas, nos vários papéis que desempenham. Assim, suas experiências de vida são entrecortadas pela separação entrelugares etempos vividos. Sendo assim, a relação que o homem estabelececom o tempo não ésimplesmente cronológica, mas principalmente demarcada pelas formas que vivenciam as experiências de vida no tempo. Assim, no trabalho offshore, essa vivência com o espaço e o tempo assume um significado especialmente particular, de um tempo que parece não passar.

A organização do trabalho explora essa percepção e condição, na medida em que os próprios trabal hadores expressam que o ritmo intenso do trabalho Ihes dá uma sensação de uma maior rapidez no tempo de embarque. É como se o tempo fosse rapidinho (Trabalhador entrevistado).

0 trabalhador, nessa condição de isolamento, se percebe como um prisioneiro, disposto a aventurar-se, no limite do suportável da vida intermitente, mas optando pelos ganhos salariais, em troca do seu sacrifício e daqueles com quem convive. 0 efeito que o totaliza vai gradativamente moldando a sua identidadenum processo contínuo ecrescente dealienação. Numa primeira fase, que vai provavelmente até os cinco ou oito anos iniciais de embarque, ainda se questiona sobre o custo de sua vida fragmentada. Em uma etapa seguinte, reverter significa tomar uma decisão para desembarcar, o que se torna muito difícil de ocorrer. U ma fala recorrente é: M inha vida está toda estruturada desse jeito, agora é tocar, é ligar o automático (Trabalhador entrevistado). Assim, a alienação enquanto um processo social produz e reproduz não mais um trabalhador sujeito de sua história, mas um sujeito máquina, automatizado e totalizado.

0 depoimento abaixo apresenta dois aspectos cruciais na passagem do mundo offshore para o mundo terrestre. Um deles se refere ao impedi- mento, momentâneo, de exercitar a própria autonomia - liberdade de ir e vir - e um segundo que aponta para a dificuldade de desligamento do regime de trabalho, mesmo no período de folgas, uma vez queo efeito quetotaliza interfere, deforma contínua eintermitente, na vida do trabalhador. O ser humano não nasceu pra viver confinado. Nós não somos uma máquina pra deixar sua liberdade. Vocêchega lá a bordo, você desliga um botão e esqueci o meu problema. 0 ser humano não é. E o ambiente confinado, ele não te permite saídas rápidas. Aqui em terra, se eu tiver um problema, se eu precisar ir a um banco, precisar ir a um hospital, se eu tenho um parenteou um conhecido tá precisando de uma ajuda urgente, eu tenho como eu conversar com meu gerente e preciso dar uma saída aqui rápida e você sai e resolvee na plataforma não. Então, o confinamento éo ponto negativo (Trabalhador entrevistado).

A impossibilidade de ter livre trânsito entre os espaços offshore e terrestre destaca que cada um a seu modo tem diferentes razões para estar e permanecer nesse regime de trabalho e possuir diferentes visões e atitudes com relação ao mesmo. Assim, "o trabalho não é, portanto voluntário, mas compulsório, trabal ho forçado. [...] torna-se meio e não primeira necessidade de realização humana [...] $]^{12 " . ~ N ~ N e s s e ~ p r o c e s s o ~ c o n t r a d i-~}$ tório, o trabalhador alienado não se vê implicado, mas ao mesmo tempo se percebe isolado, sujeitado e não sujeito.

Embora a liberdade enquanto a possibilidade de escolher com autonomia, de modo consciente e livre, entre estar no mundo de casa ou da rua $^{13}$, seja sempre relativa, no trabal ho offshore essa possibilidade, além de se agravar, se submeteà determinação deuma escala de trabal ho. Isso é indicativo de uma lógica produtiva que não estabelece uma posição intermediária entre estes dois universos, mar (rua) e terra (casa). Quem ou o que vai permitir que o trabalhador possa migrar temporariamente para o território de sua casa é o calendário.

É como viver em capítulos. N ossos desejos, nossas vontades estão sen do definidos em pacotes de 21 dias. Você não vive os 365 dias do ano, você vive pedaços desse ano, que vão se encaixar, da forma que a empresa quiser. Vocênão pode escol her, querer embarcar. A nossa vida de embarcado quem defineéa escala. Então, somos quaseescravos dessa escala (Trabal hador entrevistado).

Nós somos mandados e governados pelo nosso calendário (Trabalhador entrevistado).

0 que marca mais esse regime de trabal ho são muitas datas que a gente perde de estar com a fa- 
mília. Aniversário de mãe, filho, esposa, namorada, pai, do amigo. No Natal, no Ano N ovo e pra alguns o carnaval. Eu via colegas ficarem desolados. 0 que marca muito no trabalho éesselance de perder muito o contato de certas pessoas no período festivo (Trabalhador entrevistado).

Estar impossibilitado de participar de eventos de significativa carga simbólica, como al guns citados acima, constitui um enorme sentimento de frustração para os trabalhadores e para aque les que deixam em terra.

A ambiguidade de significados que perpassa o mundo offshore remete 0 trabalhador à condição de prisioneiro de um regime de trabalho que contraditoriamente 0 encarcera e 0 liberta. Essa concepção de prisão pode posicioná-los como os novos escravos de um mundo que apenas os reconhece através dos recordes, dos prêmios e dos desafios, mas os desconhece en quanto sujeitos de uma experiência particular em que vivem. Passam a ser escravos de sua própria experiência e "ficam simbolicamente confinados"14.

0 ciclo embarque/desembarque, além de de sorganizar a vida social, cultural, educacional, esportiva e o lazer, também interfere de modo incisivo no relacionamento conjugal. Enquanto que, para alguns trabalhadores, o distanciamento da família, de modo intermitente, pode gerar desestruturação familiar, levando à dissolução do relacionamento, para outros, a sensação de ausência irrecuperável do tempo e espaço, por parte do trabalhador, o coloca confinado em suas angústias, sendo exigido que se submeta a um novo condicionamento, agora, distante do sistema contínuo que não admite a ocorrência de falhas.

Losicer eSiqueira ${ }^{6}$ consideram que, apesar das plataformas estarem submetidas a um efeito que as totaliza, por terem alguns traços característicos das instituições totais citadas por Goffman ${ }^{5}$, as particularidades existentes nesseespaço institucional evidenciam diferenças determinantes, porque o sujeito embarcado, além de optar por ser um "prisioneiro voluntário", "disposto a aventurar-se a trabalhar e viver nos confins do mundo psíquico, no limite do suportável, no fascinante einsano mundo das plataformas", entende que o trabal ho offshoreseconfigura como uma patologia das fronteiras, "própria das situações extremas, que gera adaptações forçadas e igualmente patológicas, mesmo sem manifestação exterior", posicionando 0 trabalhador num mundo de fronteira entre 0 normal e o patológico (psicoses e neuroses). Assim, esse quadro psíquico se caracteriza nessa re gião de fronteira, por um sistema de defesas e não por uma patologia característica dessa realidade.
0 processo de inserção no mundo offshorese dá de forma gradual. Inicialmente, o trabal hador se entusiasma pelas expectativas do "novo, do trabal ho diferente", de uma condição salarial que eleve significativamente suas condições de vida de sua família, de poder gozar de 21 dias de folgas remuneradas, de estar empregado na maior empresa da América Latina e que gradativamente vão delineando, ao longo dos anos, sua identidadeetornando mais difícil, a cada embarque, romper com esse mergulho no mundo offshore. Pessanha ${ }^{7}$ compartilha dessa concepção, por considerar que o impacto da organização do trabalho sobre esses trabalhadores é muito maior que as questões que envolvem as inovações tecnológicas nos processos de trabalho.

Alguns trabal hadores "novatos", que possuem no máximo cinco anos de embarque, independentemente do cargo que ocupam, afirmam que, apesar da alta qualidade e consistência do aprendizado no regime offshore, não se vêem nessa mesma condição de trabalho como os seus colegas mais antigos, que embarcam há mais de quinze anos. Esses novatos são apelidados de "borrachos", sendo que esta designação também é dada aos operadores novos das refinarias de petróleo ${ }^{15}$. Os "borrachos" entendem que essa experiência marítima éuma etapa, uma fase passageira. Eu tô com três anos só, e não pretendo ficar o tempo que os senhores ficaram, com certeza. A vida é uma só, você perde. U m mês tem 30 , 14, você fica embarcado, você fica longe dos seus filhos, vocêfica longe de sua esposa, de seus familiares. É um local de aprendizagem, agora não éum local pra você ficar definitivamente (Trabalhador entrevistado).

Eu não vejo assim como carreira, não vejo futuro pra mim (Trabalhador entrevistado).

Onde vive o trabalhador offshore? Onde ele está? M uitos relatos sinalizam que esses milhares dehomens vivem em um espaço etempo transitórios entre o mar e a terra. Viver na fronteira desses dois mundos é se situar num "território de ninguém"14, a não ser daqueles que vivem nas mesmas circunstâncias. Cada um ao seu modo, ao longo dos anos, vai se impondo as perdas do seu mundo de origem, mas ao qual ainda permanecepertencendo. Sendo assim, o embarcado sesitua diante do mundo deterra quenão consegue reconhecer sua singularidade, seja pelo significado simbólico que ao longo dos anos vai internalizando, seja pela intenção de preservar a família e os amigos do reconhecimento dos riscos inerentes ao próprio trabalho e realidade. 


\section{Consideraçõesfinais}

Caberia ainda ressaltar que o trabal hador offshore, enquanto sujeito histórico, como pioneiro da indústria petrolífera offshore brasileira, também sesente prisioneiro deum regime de efeito totalizante, que o controla eque não o val oriza, nem o reconhece. Sofrecom as consequências da jornada de trabalho, o confinamento, a distância de terra, de contatos com a sua rede social de relações e que não somente trabal ha no arquipélago de aço da Bacia de Campos, mas que também neste vive por catorze dias.

0 trabalhador vive conflitos etensões, deforma fragmentada e intermitente, entre o mundo marítimo eavida terrestre. 0 homem parcializado no mundo offshore, pois não Ihe é possível desempenhar outros papéis, deseja e sonha com o dia de retorno ao convívio com a família e amigos. Sonhos realizados, outros frustrados, desejos saciados, outros ainda por fazê-lo, comemorações, eventos, tempo marcado pelos acontecimentos: esse não é o tempo offshore. 0 tempo é limitado e determinado pela "escala", pela dúvida permanente entre ficar mais um pouco ou para toda vida.

N essa vida segmentada e intermitente, esses trabalhadores "como fumaça costumam sumir e reaparecer" ${ }^{\prime \prime}$.

\section{Referências}

1. Leite RM . 0 trabalho nas plataformas marítimas de petróleo na Bacia de Campos: a identidade do trabaIhador offshore [dissertação]. Rio de Janeiro (RJ): Universidade Federal do Rio de Janeiro; 2006.

2. Sevá Filho A. Seguuura, Peão! Alertas sobre o risco técnico, coletivo crescente na indústria petrolífera. In: Freitas C, Porto M, M achado J, organizadores. Acidentes industriais ampliados: desafios e perspectivas para o controle e a prevenção. Rio de Janeiro: Fiocruz; 2000.

3. Sevá Filho A. Combustíveis, Trabalho Social e Risco Técnico: 0 petróleo e o gás no N orte Fluminense e no Brasil dos anos 1990 [relatório de pesquisa de pósdoutorado]. Rio de Janeiro (RJ): Coordenação dos Programas de Pós-Graduação em Engenharia, Universidade Federal do Rio de Janeiro; 1997.

4. Brasil. Constituição Federal. República Federativa do Brasil. Brasília: Centro Gráfico do Senado Federal; 1988.

5. Goffman E. M anicômios, prisões e conventos. São Paulo: Perspectiva; 1987.

6. Losicer E, Siqueira Silva V. Relatório do projeto de intervenção clínico-institucional. M acaé; 1991. [M imeo]

7. Pessanha R. 0 trabalho 'offshore': inovação tecnológica, organização do trabalho e qualificação do operador de produção na Bacia de Campos [dissertação]. Rio de Janeiro (RJ): COPPE, Universidade Federal do Rio de Janeiro; 1994.

8. Figueiredo M. O trabalho de mergulho profundo em instalações petrolíferas offshore na Bacia de Campos: confiabilidade e segurança em meio à guerra de "highlander' contra leviatã [tese]. Rio de Janeiro (RJ): COPPE, Universidade Federal do Rio de Janeiro; 2001.
9. Siqueira Silva V. Os transtornos mentais que acometem os embarcados. M acaé; 1997. [M imeo]

10. Jobim e Souza S. Infância e linguagem: Bakhtin, Vygotsky e Benjamin. São Paulo: Papirus; 2004.

11. Athayde M. Gestão de coletivos de trabalho e modernidade: questões para a engenharia de produção [tese]. Rio de Janeiro (RJ): COPPE, Universidade Federal do Rio de Janeiro; 1996.

12. Antunes R. Adeus ao trabalho? Ensaio sobre as metamorfoses e a centralidade do mundo do trabalho. São Paulo: Cortez; Campinas: Editora da Universidade Estadual de Campinas; 1998.

13. Da M atta R. A casa \& a rua. Rio de Janeiro: Guanabara Koogan; 1991.

14. Losicer E. Caso clínico em alto mar: abrindo a "caixa preta" da P-36. In: VIII Colóquio Internacional de Sociologia Clínica e Psicosociologia; 2001; Belo Horizonte. [M imeo]

15. Ferreira $L$, I guti $A$. 0 trabalho dos petroleiros: perigoso, complexo, contínuo e coletivo. São Paulo: Scritta; 1996.

16. Pessanha R. Heróis do petróleo. Campos: ONG 21; 2001. [M imeo]

Artigo apresentado em 27/09/2007

Aprovado em 27/06/08

Versão final apresentada em 10/09/08 